\title{
Internationalization and the Creation of New Products and Processes in the Mexican Manufacturing Industry
}

\author{
Liliana Meza González \\ Centro de Investigación y Docencia Económicas, México City, México
}

\begin{abstract}
This paper analyzes the relationship between internationalization and the generation of new products and processes, using data from 2,285 Mexican manufacturing firms during the 2008-2009 period. The purpose is to understand how the insertion in international markets, either through exporting, importing, receiving foreign direct investment, or outsourcing affects the innovative outcomes of manufacturing firms. Using logistic regressions, this paper contributes to the literature analyzing the case of a single developing country and concludes that, after controlling for the size of the firm, its innovative effort, and the market concentration of the industry where the firm is situated, exporting does not promote product or process innovations but promotes the generation of innovation for the world; being an importer does not affect the innovative outcomes of the firm; Foreign Direct Investment (FDI) also promotes innovation for the world, while outsourcing inhibits the generation of both products and innovations for the world. Keywords: technological innovation, economic integration, manufacturing sector, Mexico, developing country, outsourcing
\end{abstract}

\section{Introduction}

The internationalization of firms in developed countries and the correlation with its productive performance has been a topic widely discussed in the literature (see, for example, Qian \& Li, 2002; Contractor, Kundu, \& Hsu, 2003; Thomas \& Eden, 2004; Bernard, 1999). In these countries, the idea that more productive and efficient companies are self-selected in order to perform in the international market, which at the same time makes them improve their performance, prevails. This causes the correlation, whether linear or curvilinear, between the performance and the internationalization of a firm easy to find through different empirical exercises.

Internationalization is understood as the expansion of the private companies or their markets beyond the borders or towards areas or countries at different geographical points (Hitt, Hoskisson, \& Kim, 1997, p. 767). The relationship that the internationalization has with the innovation, taking into account that the innovative capacity of a company can be considered as an indicator of its performance, has also drawn several analysts' attention. In this field, the studies about the roles of the exports in the innovative effort of the productive unities are highlighted by their importance. The main finding in these researches is that the search for external markets promotes innovative activities, and that as imports of goods increase, the easier is the entrance to international markets. In this sense, there is a consensus regarding that a major internationalization generates incentives to

Liliana Meza González, associate professor, Centro de Investigación y Docencia Económicas, México City, México.

Correspondence concerning this article should be addressed to Liliana Meza González, Centro de Investigación y Docencia Económicas, Economics Division Carretera, México-Toluca \# 3655 Col. Lomas de Santa Fe, Delegación Alvaro Obregon, c. p. 01210, México City, México. 
innovate, and that the innovation at the same time facilitates the internationalization (see Altomonte, Aquilante, Békes, \& Ottaviano, 2013).

According to the Oslo Manual, innovation is defined as "the generation of new products and processes technologically implemented, and substantive technological improvements in products and processes” (OCDE, 1997, p. 31). Therefore, when analyzing innovation at the level of the companies, it is recommendable to focus on the results, and not on indirect measures of innovation such as research and development effort (R\&D) or patent registration ${ }^{1}$.

The papers that analyze the relationship between internationalization and innovation in developing countries are scarce, and their conclusions are ambiguous. For example, Damijan, DeSousa, and Lamotte (2009) state that for some economies in transition, exporting to developing countries promotes organizational learning, while exporting to developed economies does not. Furthermore, Damijan, Kostevc, and Polanec (2010) state that exporting from a country in transition facilitates process innovation, but not innovation in products. Recently, Boermans and Roelfsema (2015) have concluded that the internationalization of companies in some economies in transition increases the propensity to innovate due to higher competition to which these companies are exposed on the international markets or before the imports. Older papers, theoretical as well as empirical, have found that the internationalization promotes the adoption of foreign technologies but not necessarily the creation of new products and processes (see Almeida \& Fernandes, 2008) 2 .

The internationalization of a company can be done by the sales in external markets (exports), by inputing purchase in other countries (imports), by capital investment from other nations (FDI), or by a combination of all three elements. The process of outsourcing (or maquiladora) is also an integration mode where the FDI is combined with the exports. Given the fact that Mexico is a country where the outsourcing industry represents an important proportion of the manufacturing sector, in this paper, the outsourcing will also be included in the analysis. For purposes of this research, and since internationalization refers to a variety of factors, this concept will also be called "international diversity".

The theoretical literature about FDI and innovation arguments that the external investments generate technological spillovers in the domestic productive sector, which implies that the social benefits of the FDI exceed the private benefits (see Cantwell, 1989). For example, if the increasing of foreign capital in an industry promotes increases in productivity of companies of the same industry by means of new knowledge which is converted, at least partially, into a public good, then a technological spillover is generated (Haskel, Pereira, \& Slaughter, 2007). Different empirical studies, however, have shown that the FDI in developing countries does not only not provoke technological spillovers, but also inhibits the creation of new goods and production techniques since it promotes the adoption of technology in the subsidiary companies used in the mother company, or even obsolete technology (Mansfield \& Romeo, 1980; Ramachandran, 1993; Javorcik, 2006). This can be partly explained because foreign companies tend to prefer markets protected from the competition (Haddad \& Harrison, 1993) ${ }^{3}$.

\footnotetext{
${ }^{1}$ According to Becheikh, Landry, and Amara (2006), the patent registration shows the inventive capacity of a company and not necessarily its capacity to generate innovations. Besides, the R\&D effort is considered as an input of the innovation but not its result.

${ }^{2}$ In developing countries, it is difficult to distinguish the innovation based on the adoption of foreign technology of the innovation which implies the generation of new products for the world.

${ }^{3}$ According to Seker (2012), the companies with foreign capital tend to use more modern technology and to apply more productive production methods than those used in the national companies. Therefore, although they grow faster, they have less necessity to improve their products and processes when compared to the national companies.
} 
Capital imports can also inhibit the development and the creation of new products and processes and facilitate the adoption and the copy of the technology incorporated in the machinery and the goods from abroad (Grossman \& Helpman, 1991) ${ }^{4}$. The exports can also generate a competition dynamic that reduces the incentives to generate new goods and processes, and encourage the creation of products and the adoption of technology already tested in the international markets (Comin \& Hobijn, 2004; Caselli \& Coleman, 2001).

Given that the effect the international diversification has over the generation of new products and processes in companies of developing countries is not clear, this paper tries to provide evidence to this literature through an analysis at microeconomic level, and with data of the Mexican manufacturing industry during the years of 2008 and 2009.

This research is organized as follows. The first section includes a short introduction. The second section presents a revision of the literature about the role of international diversification in the generation of new products and processes, and the adoption of existing technology. The third part describes the source of the data and presents a descriptive analysis of the innovative activity in Mexico. The fourth section discusses the methodology of estimation while the fifth shows the results of the econometric analysis. The sixth part discusses the results and the seventh and last part includes some reflections as a conclusion.

\section{Literature Review}

The effect of the internationalization of a developing country or its companies on technological innovation is quite a new topic in the literature. The innovative efforts in developing or in countries in transition are related to their integration with the world, since it allows them the access to new markets and to the knowledge of leading-edge technologies through the FDI and the capital import. However, the innovation generated by the internationalization of a developing country can stay in the adoption of developed technologies tested in developed countries, and not to provoke the generation of novelties to the firm, the country or the world, which in the long term can limit economic growth ${ }^{5}$.

Several analysts have written about the role of FDI and trade on the technological advance in the developing countries. Some of these studies relate the technology advance with the changes in Total Factor Productivity (TFP), which according to Alvarez and Robertson (2004) not always is correct since, when the TFP is calculated, the productivity is measured as a residual; and hypothetically anything that is not included in the estimated equation could contribute to increasing this productivity. Besides, different ways of measuring productivity and the inclusion of different explanatory variables have generated contradictory results, which have provoked that many scholars opted for measuring the technological advance by means of variables most related to the technological behavior of the companies (R\&D expenditure, patent registration, creation of new products and processes, etc.). However, the results of these studies not always coincide, which allows concluding that there is no consensus about the role of the integration into the international markets on

\footnotetext{
${ }^{4}$ According to these authors, the countries that import goods from nations technologically more advanced are more exposed to technological development and tend to adopt these technologies more easily. This can be called "push-factor". The foreign technology adoption is considered innovation in the company but this type of innovation is not analyzed in this paper.

5 The theory of economic growth establishes that the technological improvements in the productive sector affect the long-term growth in a positive way (Romer, 1990; Aghion \& Howitt, 1998). In more specific way, scholars who study growth have found that the technological advances in the companies influence the total productivity of the factors and that the differences in technology explain an important part of the differences in the productivity of the factors, both between countries and industries (Griliches, 1998).
} 
technological advance in a developing country ${ }^{6}$.

There are several papers that analyze the effect of internationalization on innovation in developing countries through micro analysis, in which data of companies from different countries are combined. The studies that use data from one single country in order to study the relationship between internationalization and innovation, make reference to developed countries; that is why this paper contributes to the knowledge of this topic through examining the case of a developing country. Among the first type papers (at the country level), Almeida and Fernandes (2008) stand out, who used cross-section data of 43 developing countries in order to analyze the role of exports, imports, and FDI on technological "adoption"7. Their results suggest that both imports and exports promote technological advance, but indicate that the companies that are foreign in their majority tend to innovate less than their national counterparts, or that the companies that are foreign in their minority. They conclude that the technology transferred by the mother companies to their subsidiaries is more mature than the technology transferred by the same companies to companies that are not subsidiaries. Finally, they indicate that the subsidiaries and companies with foreign capital become dependent on the technology they receive from mother companies.

Another research that analyzes data of developing countries and tries to explain the role of internationalization on the innovative efforts of the companies belongs to Seker (2012). This author uses data from 16,722 manufacturing companies from 43 developing countries and tries to determine whether the companies that are international traders in two senses (i.e. both exporter and importer) have higher performance in comparison with the companies that only export or only import. This paper considers the innovation as an additional indicator of business performance, and concludes that the exporting and importing companies tend to be more innovative, followed by exporting and then by importing companies. The least innovative companies are the ones that do not trade abroad. An interesting conclusion of this paper is that the companies that have a relation abroad are generally bigger and more productive, and grow more than their counterparts. In this article, the innovative effort of the companies is measured by means of creation of new products and processes, use of quality certificates (like ISO9000), and by means of the use of foreign licenses.

A more recent research, in which data from different developing countries are used, was done by Boermans and Roelfsema (2015). After having analyzed 1,355 companies in 10 countries in transition, they conclude that the internationalization increases the tendency of the companies to innovate, and specifically found that the outsourcing (maquila) promotes product innovation, while exports and FDI are associated with higher R\&D expenditure and a higher patent registration.

Besides the researches that use data from different countries, there are works that use information of one or two countries in order to understand the determinants of the generation of new products and processes, and the adoption of foreign technology at the industry or firm level. However, the majority of these papers refer to the experience of developed countries. An interesting research of a country was done by Bertschek (1995). This author, with data of German companies, found that both FDI and imports have positive effects on the innovative activity of the national productive sector. This is because the integration into the international

\footnotetext{
${ }^{6}$ Theoretically, the internationalization of a company has a positive influence on the technological advance. The problem with this affirmation is that the technological advance can be within the technological frontier (which implies an imitation or adoption of existing technology) or outside of it (innovation for the world). See Bertschek (1995).

${ }^{7}$ For Almeida and Fernandes (2008), the measure of the technological advance is a dummy which is equal to one if a company reports having introduced new technology that substantially changed its main product production three years before the inquiry. This technology could have been created by the company or could have been imported.
} 
markets influences the level of competition that the productive units face, which generates the necessity to perform with higher efficiency in order to maintain the competitiveness and, therefore, the participation in the market. In this paper, the concept of innovation refers to the generation of new products or new productive processes; therefore, this analysis resembles the present one, although the reaction of the productive sector of a developed country is probably different to the one of a developing country. In Bertschek's research, panel data for the time period 1984-1988 are used and make use of probit estimates since its dependent variables are binary. The author argues that her conclusions contradict the existing literature in the sense that not always the FDI and the imports are found to promote the creation of new products and processes.

Bertschek's work reaffirms the results of a research that also uses data of German companies, but for the time period of 1981-1982. This paper, made by Zimmermann (1987), tried to establish the relation between internationalization and the creation of new products and processes. The author points out that for the companies that face competition from international markets, it is easier to imitate the technology than to generate it, which is fully rejected with his econometric work. Zimmerman's results indicate that the exports and the demand for imports promote the creation of new goods and new production techniques; however, he found that the export activity decreases the effect of company's size and the market power on process innovation. In this regard, it is worth mentioning that both the size of the company and its market power are variables that theoretically explain the innovative capacity of the productive units. According to Schumpeter (1934), the technology innovation is generated basically in large companies. This idea led to the creation of the concept "economies in scale in research and development". In 1965, Frank Schrerer (1965) suggested that the relationship between the size of a company and its innovative effort was not lineal since the innovative effort was increasing at a decreasing rate with the size of a productive unit. Regarding the market power, the economic theory establishes that the companies with greater monopoly power lack incentives to innovate; the same as the companies that work on perfectly competitive markets (see Dasgupta \& Stiglitz, 1980).

Other paper at a national level, although also deals with the case of a developed country, was written by Criscuolo, Haskel, and Slaughter (2010). According to this research, the companies globally committed (the multinational and the exporters) tend to be more productive, and to innovate more than their national counterparts. This paper uses data from 8,242 British companies for the time period 1994-2000, and concludes that behind the high innovative capacity of the internationalized companies, there is their capacity of learning and their capacity of assimilation of the information from their suppliers, their clients, and the universities.

Regarding developing countries and, specifically, the case of Mexico, there is a paper that analyzes the effect of the exposition to international markets on innovation with data from Mexico and Chile. This research was done by Alvarez and Robertson (2004) at production plant level using cross-sectional methodology. Their dependent variables are seven different measures of technological advance: innovation of product design, research and development (R\&D) laboratory, new productive process, ISO9000, foreign licenses, product, and organization innovation. The authors found out that both FDI and trading positively affect the rate to which companies generate new products and new productive processes, and concluded that the effects of these variables on the innovation efforts are stronger in Mexico than in Chile and, according to what they point out, a recent internationalization process has more effect on the technological advance than a more consolidated one.

Another work that uses information from companies in a developing country was written by Insik (2003). This author analyses the effect of international diversification on the product innovation using data from 179 United States companies and 250 Chinese companies. The research shows that the international diversification 
has a positive effect on the product innovation, but this effect is greater for US companies than for Chinese. In fact, the research concludes that in the case of Chinese productive units (i.e. those belonging to a developing country), the product innovation decreases after certain internationalization threshold. An interesting result of this research is that the size of the company is an important determinant of the innovation only in the case of the Chinese companies, but not in the case of the US companies.

According to the literature revision, there are no researches so far that relate FDI, exports, imports, and outsourcing to the creation of new products and processes in a single developing country. Almost all researches that analyze the relation between internationalization and innovation in developing countries use as proxy of the last the expenditure in R\&D. Moreover, a lot of researches that address this topic are concentrated on one measure of internationalization and not in many. A recent example of this type of researches has been done by Anwar and Sun (2013), who analyzed the effect of the FDI on the investment in R\&D with data of Chinese manufacturing companies for the period 2005-2007. The objective of these authors was to understand the effect that foreign investment has on the innovative efforts of national companies. Through a panel analysis, the scholars conclude that the presence of foreign companies promotes more competition on the markets, and incentives the national companies to invest more in research and development. The reviewed literature allows concluding that in order to understand the effect of the internationalization of a group of companies on their innovative efforts, it is necessary to do econometric estimates, which control for both the size of the productive unit and the degree of market concentration of the industry in which each company of the sample is inserted. Furthermore, and in order to take into account the innovative effort of the company, a variable which denotes interest in improving technology in each productive unit must be included in the regressions, such as the presence of an R\&D laboratory. The use of panel data is recommended in order to control for specific factors of the companies which can affect their propensity to innovate.

The following section includes the descriptive analysis of the information contained in the Survey of Research and Technological Development of 2010.

\section{Data}

The firm level data used in this paper to analyze the relationship between internationalization and technological innovation (measured by the generation of new products and processes) come from the Survey of Research and Technological Development (ESIDET) of 2010, which collects the information for the years 2008 and 2009. This survey is lifted by the Mexican National Institute of Statistics and Geography (INEGI). The objective of the ESIDET is to capture and generate information related to the human and financial resources dedicated to activities related to Research and Technology Development in non-profit private, higher education, governmental and productive sectors; to know the conduct of these activities through international cooperation as well as the factors that favor and hinder technological innovation in the Mexican productive sector (INEGI, 2013). The ESIDET follows the methodology of the Frascati Manual of the Organization for Economic Co-operation and Development (OECD) and has been lifted every two years in the period of 2000-2012. At the moment this research was performed, the INEGI had not released the results of the ESIDET 2012. The ESIDET is applied to a representative sample of firms at a national level, and among the companies that have more than 20 employees in Mexico.

To understand the effect of the internationalization of the Mexican manufacturing companies on the generation of new products and processes, the term "internationalized" company should first be defined. For 
purposes of this investigation, an internationalized company is a company which sells part of its production on international markets (exporter), or has a foreign supplier (importer), or that part of its capital comes from another country (Inward Foreign Direct Investment). The outsourcing companies were also included in this definition; i.e., those which have $100 \%$ of foreign capital, and export more than $98 \%$ of their production. It should be mentioned that, in this definition, the companies that invest part of their capital abroad are not included (Outward Foreign Direct Investment). Table 1 includes basic information about the firm sample used in this research.

Table 1

Basic Statistics. Expanded Data With ESIDET 2010 Factors

\begin{tabular}{llll}
\hline & Average & Stand. dev. & Total companies \\
\hline 100\% foreign company & 0.1173 & 0.3218 & 2,285 \\
Mixed capital company & 0.0337 & 0.1804 & 2,285 \\
$100 \%$ national company & 0.8489 & 0.3581 & 2,285 \\
Exporting company & 0.1858 & 0.3891 & 2,285 \\
Importing company & 0.1723 & 0.3778 & 2,285 \\
Outsourcing company & 0.0565 & 0.2310 & 2,285 \\
Company with license & 0.0154 & 0.1233 & 2,285 \\
Size & 145.85 & 442.13 & 2,285 \\
Concentration & 0.3261 & 0.1572 & 2,285 \\
\hline
\end{tabular}

Source: Own estimates with dates of the ESIDET 2010.

According to Table 1, $11.7 \%$ of the companies from the sample (expanded with expansion factors of the ESIDET) have $100 \%$ of foreign capital, while only $3.4 \%$ have mixed capital (national and foreign). This implies that $84.9 \%$ of the sample are companies with $100 \%$ Mexican capital. Also, $18.6 \%$ of the expanded sample are exporting companies, while $17.2 \%$ are companies that import part of their inputs. Only $5.6 \%$ of the sample are outsourcing companies (i.e., which have $100 \%$ of foreign capital and export more than $98 \%$ of their production). Finally, only $1.5 \%$ of the total are companies with licenses (i.e., with the permission to operate a foreign patent). The average size of sample companies is 146 employees. Furthermore, the biggest four companies of each manufacturing sector included in the analysis hold $32.6 \%$ of the total sector income (measure of market concentration). The total number of sample companies is 2,285.

Table 2 shows the basic statistics of some variables related to the generation of new products and processes.

According to the estimates, $12.8 \%$ of all companies of the expanded sample carried out, in 2008 or 2009, some product innovation, and $7.2 \%$ carried out a process innovation. The fact that draws attention is that only $0.01 \%$ of all sample companies declared an income from sales of any patented product, while $2.65 \%$ of the sample declared to have generated some innovation for the world in 2008 or 2009. The ESIDET includes also questions regarding the intention to innovate in the companies. It is observed that $14.8 \%$ of the sample companies invested in training in order to generate their own technology; and 30.9\% invested in resources in order to generate some technological innovation. To know the innovative efforts of the "internationalized" companies, and to compare them to the innovative efforts of the non-internationalized, the basic statistics of the innovation variables, according to the company type, were obtained. This information is included in Table 3. The fact that the companies with a relationship with the international markets perform better in innovation than 
the companies without exports, imports, or foreign capital, draws attention. The descriptive statistics suggest that having contact with international markets promotes greater innovation. However, so as to better understand the relationship between internationalization and innovation, some econometric estimates were carried out with which the effect that other factors have on the innovation of products and processes could be controlled, such as company size, the innovative effort of the same, and the concentration grade of the industry in which each company is inserted.

Table 2

Basic Statistics of the Innovation Variables. Expanded Data With ESIDET 2010 Factors

\begin{tabular}{llll}
\hline & Average & $\begin{array}{l}\text { Standard } \\
\text { dev. }\end{array}$ & Total companies \\
\hline Product innovation & 0.1282 & 0.3344 & 2285 \\
Process innovation & 0.0717 & 0.2581 & 2285 \\
It has income from sales of patented products & 0.0001 & 0.0108 & 2285 \\
Innovation for the world & 0.0265 & 0.1607 & 2285 \\
Invests in training to generate its own technology & 0.1478 & 0.3549 & 2285 \\
Invests in generation of own technology & 0.3094 & 0.4624 & 2285 \\
\hline
\end{tabular}

Source: Own estimates with dates of the ESIDET 2010.

Table 3

Basic Statistics of the Innovation Variables for Company Type. Expanded Data With ESIDET 2010 Factors

\begin{tabular}{|c|c|c|c|c|c|c|}
\hline \multirow{2}{*}{ Dependent variables } & \multicolumn{2}{|c|}{ Total companies } & \multicolumn{2}{|c|}{ Internationalized companies } & \multicolumn{2}{|c|}{$\begin{array}{c}\text { Non internationalized } \\
\text { companies }\end{array}$} \\
\hline & Average & $\begin{array}{l}\text { Standard } \\
\text { dev. }\end{array}$ & Average & $\begin{array}{l}\text { Standard } \\
\text { dev. }\end{array}$ & Average & $\begin{array}{l}\text { Standard } \\
\text { dev. }\end{array}$ \\
\hline Product innovation & 0.1282 & 0.3344 & 0.1772 & 0.3820 & 0.0995 & 0.2994 \\
\hline Process innovation & 0.0717 & 0.2581 & 0.0910 & 0.2878 & 0.0604 & 0.2383 \\
\hline $\begin{array}{l}\text { It has incomes from the } \\
\text { patent product sales }\end{array}$ & 0.0001 & 0.0108 & 0.0002 & 0.0126 & 0.0001 & 0.0096 \\
\hline Innovation for the world & 0.0265 & 0.1607 & 0.0662 & 0.2486 & 0.0033 & 0.0574 \\
\hline $\begin{array}{l}\text { Invests in training to } \\
\text { generate its own technology }\end{array}$ & 0.1478 & 0.3549 & 0.2066 & 0.4050 & 0.1133 & 0.3172 \\
\hline $\begin{array}{l}\text { Invests in generation of own } \\
\text { technology }\end{array}$ & 0.3094 & 0.4624 & 0.4490 & 0.4975 & 0.2277 & 0.4196 \\
\hline
\end{tabular}

Source: Own estimates with dates of ESIDET 2010.

In the sample, there are 1,472 internationalized companies and 813 non-internationalized companies. Table 3 indicates that during 2008 and 2009, 17.7\% of the internationalized companies generated product innovation, while only $10 \%$ of the non-internationalized companies did it. Besides, it indicates that $9.1 \%$ of the internationalized companies generated innovation in product, while only $6.0 \%$ of the non-internationalized companies did it. The data in Table 3 also indicate that $0.02 \%$ of the internationalized companies declared incomes from patent product sales, while only $0.01 \%$ of the non-internationalized companies had incomes from patent product sales. Regarding the generation of innovation for the world, $6.6 \%$ of the internationalized companies declared to have generated this kind of innovation in 2008 or 2009 , but only $0.33 \%$ of the non-internationalized companies declared it. Moreover, data from Table 3 indicate that the companies with a relationship with the international market tend to invest more in training for their own technology generation and in their own technology generation, compared to the non-internationalized firms. 
In order to understand the relationship between the integration into international markets and the innovative activity of the companies of the Mexican manufacturing sector, an econometric analysis should be carried out. This analysis could answer the following questions: how does the foreign capital affect the product innovation? Do export activities promote more innovation for the world? Do importing companies generate more process innovation?

\section{Research Method}

In order to answer the previously raised questions, and since the analyzed dependent variables are discreet (binary), the technique of logistic regression is used, which not only allows knowing the level of association between the independent variables and the dependent variable, but also allows estimating the specific weight of each category, controlling for the other variables included in the model. In this case, three different logistic regressions are estimated, in which the dependent variables correspond to some of the innovation variables that have been analyzed in the previous section (product innovation, process innovation, and innovation for the world). It is worth mentioning that in the generation of new products and processes, there are also different grades of novelty. A product or a process can be new for a company, a country, or the world, and a greater degree of innovation is related to the generation of new products or processes for the world. The independent variables correspond to the ones included in the descriptive analysis previously exposed (capital type of the company, exporting activity, importing activity, outsourcing, company size, and measure of market concentration). An additional explanatory variable is included in order to control for the R\&D effort of the firm. This variable denotes the existence of an R\&D laboratory within the firm.

In a logistic regression, a logistic transformation of the following type to the dependent variable is applied: $\ln (p / q)$, where: $p=$ the probability that the event occurs, and $q=(1-p)$ the probability that nothing occurs. On this basis, the equation of the logistic regression is represented as follows:

$$
\ln (p / q)=\beta_{0}+\beta_{1} X_{1}+\beta_{2} X_{2}+\beta_{3} X_{3}+\ldots+\beta n X n+\varepsilon_{i}
$$

which is the same:

$$
p / q=e^{\left(\beta 0+\beta 1 X 1+\beta 2 X 2+\beta 3 X 3+\ldots+\beta n X n+\varepsilon_{\varepsilon i}\right)}
$$

In the equation, the parameters $\beta_{i}$ correspond to the estimate of the effect of each independent variable on the logarithm of the ratio of probabilities of success/failure (odds ratio). This way, the factor $e^{(\beta i)}$ would correspond to the effect of the variable $i$ on the odds ratio success/failure. Thus, a positive value of $\beta i$ corresponds to the value $e^{(\beta i)}$ bigger than the unit, which indicates that this category in particular has a positive effect on the odds ratio and, therefore the probability of success.

\section{Research Results}

The estimates for each of the following dependent variables are presented in this section: product innovation, process innovation, and innovation for the world.

\section{Product Innovation}

Table 4 includes four different models to estimate the effect of the independent variables on the product innovation. The first model includes some variables as dummy regressors, which allow identifying the companies with $100 \%$ of foreign capital, the companies with mixed capital (the national companies are the omitted category), the exporting companies, and importing companies. In the second model, the outsourcing companies were added, and those with an R\&D laboratory. This last variable was used to take into account the 
innovative efforts of the production units since they clearly affect the results of innovation, and without them this could lead to an omitted variable bias. In the third model, medium and large companies were included ${ }^{8}$, and the degree of concentration (which denotes the percentage of income of the four companies with the most income of the sector, regarding the total of income of the industry). Finally, in the fourth and the last model, fixed effects per industry were included.

Table 4

Determinants of Product Innovation

\begin{tabular}{|c|c|c|c|c|}
\hline Independent variables & Model 1 & Model 2 & Model 3 & Model 4 \\
\hline \multirow[t]{2}{*}{ Company with $100 \%$ foreign capital } & $0.7259 *$ & 1.3489 & 1.2780 & 1.1813 \\
\hline & $(-1.86)$ & $(1.44)$ & $(1.17)$ & $(0.78)$ \\
\hline \multirow[t]{2}{*}{ Mixed capital company } & $1.4531 *$ & 1.3537 & 1.2940 & 1.2582 \\
\hline & $(1.71)$ & $(1.15)$ & $(0.97)$ & $(0.85)$ \\
\hline \multirow[t]{2}{*}{ Exporting company } & 1.0546 & 1.0064 & 0.9845 & 0.9545 \\
\hline & $(0.36)$ & $(0.04)$ & $(-0.09)$ & $(-0.26)$ \\
\hline \multirow[t]{2}{*}{ Importing company } & 0.9850 & 1.0481 & 1.0089 & 0.9419 \\
\hline & $(-0.10)$ & $(0.28)$ & $(0.05)$ & $(-0.34)$ \\
\hline \multirow[t]{2}{*}{ Outsourcing company } & -- & $0.4043^{* *}$ & $0.4037 * *$ & $0.4256 * *$ \\
\hline & -- & $(-3.30)$ & $(-3.28)$ & $(-3.03)$ \\
\hline \multirow[t]{2}{*}{ R\&D laboratory } & -- & $20.955^{* *}$ & $21.362^{* *}$ & $20.586 * *$ \\
\hline & -- & $(21.44)$ & $(21.41)$ & $(20.75)$ \\
\hline \multirow[t]{2}{*}{ Medium-sized company } & -- & -- & $0.7427 *$ & 0.7869 \\
\hline & -- & -- & $(-1.65)$ & $(-1.30)$ \\
\hline \multirow[t]{2}{*}{ Large company } & -- & -- & 0.9651 & 1.0116 \\
\hline & -- & -- & $(-0.22)$ & $(0.07)$ \\
\hline \multirow[t]{2}{*}{ Degree of concentration } & -- & -- & $2.7188 * *$ & 0.9726 \\
\hline & -- & -- & $(2.85)$ & $(-0.05)$ \\
\hline Fixed effects per industry & No & No & No & Yes \\
\hline No. of observations & 2,285 & 2,285 & 2,285 & 2,285 \\
\hline Pseudo $R^{2}$ & 0.0050 & 0.3022 & 0.3072 & 0.3196 \\
\hline Log likelihood & $-1,048.29$ & -735.15 & -729.92 & -716.84 \\
\hline
\end{tabular}

Source: Own estimates based on dates of the ESIDET 2010. Notes. * significant variable at $90 \%$ confidence; ** significant variable at $95 \%$ confidence; the statistic $z$ is presented in brackets below the odds ratio.

The results of the first column in Table 4 indicate that the companies with $100 \%$ foreign capital tend to innovate in product $27.4 \%$ less than the companies with $100 \%$ national capital (the omitted category), and the companies with mixed capital tend to innovate in product $45.3 \%$ more than the companies with national capital. In this first exercise, the exporting companies do not seem more likely than non-exporting firms to innovate, and the importing companies do not seem more likely than the non-importing to innovate.

The results of Model 2 are shown in the second column of Table 4. Once the outsourcing companies and the companies with R\&D laboratory are incorporated in the regression, it is observed that the negative effect of the companies with $100 \%$ foreign capital on the product innovation disappears, which suggests that it is the

\footnotetext{
${ }^{8}$ Medium-sized companies are those with between 100 and 250 employees, and large companies are those with more than 250 employees. Small companies are the omitted category and have between 20 and 100 employees.
} 
maquila companies, and not the foreign companies per-se, which promote less innovation. In fact, according to the results, the outsourcing or maquila companies are $59.6 \%$ less prone to innovate in product than the non-outsourcing companies. Moreover, the companies with an R\&D area (those which make an effort to innovate) are logically more prone to innovate in product. The rest of the variables are not significantly different from zero, which implies that they do not affect the probability of innovating in products.

The third column of Table 4 shows the results of the third model, which adds as independent variables the degree of concentration of the industry, and the company size (classified as medium and large companies, where small business is the omitted category). In this regression, the outsourcing companies show a significantly lower propensity to innovate than the non-outsourcing companies (they innovate $59.6 \%$ less). The companies with an $R \& D$ area (i.e., those which present innovative efforts) are the most prone to innovate in product. In this regression, the more concentrated companies show more propensity to innovate in product, as predicted by the theory ${ }^{9}$. When the fixed effects by industry are included (Model 4), then the outsourcing companies innovate $57.4 \%$ less than the non-outsourcing companies. Once again, the R\&D efforts positively and significantly affect the propensity to innovate in product.

This first exercise suggests that the Mexican companies dedicated to manufacture for export based on imported inputs promote less product innovation, which implies that this can be a factor behind the little innovation generated in the Mexican manufacturing sector. Moreover, the results also indicate that the companies with more innovative effort tend to generate more new products. Besides, the regression indicates that small companies are more innovative than their counterparts of larger size. Export and import, along with FDI, do not seem to promote product innovation.

The econometric exercises for the variable "process innovation” will be presented as follows.

\section{Process Innovation}

Table 5 includes four different regressions to estimate the effect of the independent variables on the process innovation. The first regression only includes, as regressors, some dummy variables which show the companies with $100 \%$ of foreign capital, the companies with mixed capital (the national companies are the omitted category), the exporting companies, and importing companies. In the second model, dummy variables for the outsourcing companies and the companies with an R\&D laboratory are added. In the third model, dummies for medium and large companies are included and also a continuous variable for the degree of concentration (which denotes the percentage of income of the four companies with the largest income of the sector). Finally, in the fourth and last model, fixed effects by industry are included.

According to the results of the first column of Table 5, a company of $100 \%$ foreign capital has a negative influence on the process innovation (this company type innovates $35.6 \%$ less than the companies with national capital, which is the omitted category). Also, an exporting company has a positive influence on the probability of process innovation (this company type innovates $46.7 \%$ more than the non-exporting companies). The importing companies do not present greater tendency to innovate in process, in comparison to the non importing companies. When the outsourcing companies and the companies with an R\&D laboratory are added to the model, it was found that the negative effect of $100 \%$ foreign companies disappears, which suggests that specifically outsourcing companies have a negative influence on the innovation probability (these companies have $38.1 \%$ less probability to innovate in process with respect to their non-outsourcing counterparts). Also, an

${ }^{9}$ The causality between two variables is not easy to establish since the innovation can provoke higher market concentration. 
exporting company has a positive influence on the probability of process innovation (this company type innovates 39.4\% more than the non-exporting). Finally, having an R\&D laboratory has a positive effect on the probability to process innovation, since these companies innovate substantially more than the companies without this laboratory.

Table 5

Determinants of Process Innovation

\begin{tabular}{|c|c|c|c|c|}
\hline Independent variables & Model 1 & Model 2 & Model 3 & Model 4 \\
\hline \multirow[t]{2}{*}{ Company with foreign capital } & $0.6435^{* *}$ & 1.0509 & 0.9848 & 0.9702 \\
\hline & $(-2.10)$ & $(0.21)$ & $(-0.06)$ & $(-0.13)$ \\
\hline \multirow[t]{2}{*}{ Mixed capital company } & 1.2970 & 1.2154 & 1.1536 & 1.1487 \\
\hline & $(0.98)$ & $(0.67)$ & $(0.49)$ & $(0.47)$ \\
\hline \multirow[t]{2}{*}{ Exporting company } & $1.4667 * *$ & $1.3936^{*}$ & 1.3252 & 1.2996 \\
\hline & $(2.18)$ & $(1.80)$ & $(1.49)$ & $(1.36)$ \\
\hline \multirow[t]{2}{*}{ Importing company } & 1.0470 & 1.1038 & 1.0677 & 1.0764 \\
\hline & $(0.25)$ & $(0.52)$ & $(0.34)$ & $(0.38)$ \\
\hline \multirow[t]{2}{*}{ Outsourcing company } & -- & $0.6192 *$ & 0.6199 & 0.6595 \\
\hline & -- & $(-1.61)$ & $(-1.60)$ & $(-1.36)$ \\
\hline \multirow[t]{2}{*}{ R\&D laboratory } & -- & $14.883^{* *}$ & $14.812^{* *}$ & $14.280 * *$ \\
\hline & -- & $(15.71)$ & $(15.66)$ & $(15.16)$ \\
\hline \multirow[t]{2}{*}{ Medium-sized company } & -- & -- & $0.6349 * *$ & $0.6753 *$ \\
\hline & -- & -- & $(-2.10)$ & $(-1.79)$ \\
\hline \multirow[t]{2}{*}{ Large company } & -- & -- & 1.0673 & 1.0913 \\
\hline & -- & -- & $(0.36)$ & $(0.47)$ \\
\hline \multirow[t]{2}{*}{ Degree of concentration } & -- & -- & 1.4060 & 0.7147 \\
\hline & -- & -- & $(0.85)$ & $(-0.50)$ \\
\hline Fixed effects per industry & No & No & No & Yes \\
\hline No. of observations & 2,285 & 2,285 & 2,285 & 2,285 \\
\hline Pseudo $R^{2}$ & 0.0061 & 0.2234 & 0.2280 & 0.2383 \\
\hline Log likelihood & -760.97 & -594.54 & -591.09 & -583.15 \\
\hline
\end{tabular}

Source: Own estimates based on dates of the ESIDET 2010. Notes. ${ }^{*}$ significant variable at $90 \%$ confidence; ${ }^{* *}$ significant variable at $95 \%$ confidence; the statistic $z$ is presented in brackets below the odds ratio.

When more explanatory variables are added to the logistic regression (third column), it is observed that the positive effect on process innovation of the export companies is eliminated, while the effect of the R\&D laboratory is maintained. The negative effect of the outsourcing companies on process innovation also disappears, while medium companies show a lower probability to innovate relative to the small companies (which is the omitted category).

The results of Model 4 are very similar to the ones of Model 3, but since the particularities of each of the industries analyzed are taken into account, they are considered superior. The last column of Table 5 indicates that the companies with an R\&D laboratory are more prone to innovate in process than the companies that do not invest in an R\&D laboratory. Once again, the probability of process innovation is lower in medium size companies, relative to small companies (the medium-sized companies innovate for $32.5 \%$ less in process than small companies). 
The results of Table 5 indicate that the internationalization of a company has no significant effect on process innovation, when the R\&D investment is taken into account. This means that small and large companies with an R\&D laboratory are the most prone to innovate in process, regardless of the relationship with the international economy. The results of the regressions of the variable: innovation for the world, are presented as follows.

\section{Innovation for the World}

Table 6 includes four different models to analyze the effect of the independent variables on the innovation for the world. The independent variables of each model are the same as in the previous regressions.

Table 6

Determinants of Innovation for the World

\begin{tabular}{lllll}
\hline Independent variables & Model 1 & Model 2 & Model 3 & Model 4 \\
Company with foreign capital & 1.2841 & $2.5121^{* *}$ & $2.3682^{* *}$ & $2.2198^{* *}$ \\
& $(0.96)$ & $(3.38)$ & $(3.11)$ & $(2.82)$ \\
Mixed capital company & $2.5707^{* *}$ & $2.7330^{* *}$ & $2.6389^{* *}$ & $2.6137^{* *}$ \\
& $(3.01)$ & $(2.99)$ & $(2.87)$ & $(2.79)$ \\
Exporting company & $2.5180^{* *}$ & $2.6863^{* *}$ & $2.5096^{* *}$ & $2.4855^{* *}$ \\
& $(3.97)$ & $(4.27)$ & $(3.89)$ & $(3.75)$ \\
Importing company & 0.9219 & 1.1317 & 1.1150 & 1.0856 \\
Outsourcing company & $(-0.35)$ & $(0.52)$ & $(0.46)$ & $(0.34)$ \\
R\&D laboratory & - & $0.5176^{* *}$ & $0.5088^{* *}$ & $0.5475^{*}$ \\
Medium-sized company & -- & $(-2.04)$ & $(-2.09)$ & $(-1.80)$ \\
& -- & $25.4083^{* *}$ & $25.3783^{* *}$ & $24.4831^{* *}$ \\
Large company & -- & $(11.90)$ & $(11.87)$ & $(11.52)$ \\
& -- & -- & 1.0342 & 1.2046 \\
Degree of concentration & -- & -- & $(0.11)$ & $(0.60)$ \\
Fixed effects per industry & -- & -- & 1.3695 & 1.4296 \\
No. of observations & -- & -- & $(1.26)$ & $(1.41)$ \\
Pseudo $R^{2}$ & -- & -- & 1.0531 & 0.4903 \\
Log likelihood & -- & -- & $(0.10)$ & $(-0.75)$ \\
\hline
\end{tabular}

Source: Own estimates based on dates of the ESIDET 2010. Notes. ${ }^{*}$ significant variable at $90 \%$ confidence; ${ }^{* *}$ significant variable at $95 \%$ confidence; the statistic $z$ is presented in brackets below the odds ratio.

The first column of Table 6 indicates that the companies of mixed capital innovate for the world $157.1 \%$ more than the companies with national capital (which are the omitted category), and that the exporting companies innovate for the world $151.8 \%$ more than the non-exporting companies. When more variables to Model 1 were added, the significance and the sign of the companies of mixed capital and the exporting companies do not change, which implies that these results are robust. In Model 2, it is observed that the outsourcing companies innovate for the world $48.2 \%$ less than the non-outsourcing companies, which somehow reinforces the finding in Table 4, that an outsourcing company has a negative influence on the probability to innovate. In the second model, it is also observed that the existence of an R\&D laboratory, or an innovative 
effort, has a positive and significant influence on the probability to innovate for the world. In this model, it is also observed that the companies with 100\% foreign capital innovate $151.2 \%$ more than the companies with national capital, which contradicts the findings in the previous regressions in some way.

In the third model, the size of the company is added to the regression (through the inclusion of dummies for the medium-sized and large companies) and the degree of concentration of the industry in which each company is inserted. In this model, the significance and the sign of exporting companies, companies of mixed and foreign capital, outsourcing companies, and the companies with an R\&D laboratory do not change, which suggests that exporting increases the probability to innovate for the world $150.9 \%$, while having $100 \%$ foreign capital increases the probability to innovate for the world $136.8 \%$. Being a company with mixed capital increases the probability to innovate for the world $163.9 \%$, and being an outsourcing company has a negative effect on the probability to innovate for the world of $49.1 \%$. Finally, the most important predictor of an innovation for the world is the presence of an R\&D laboratory inside the firm.

In the fourth model, fixed effects per industry are included. In the last exercise, it is observed that a foreign company innovates $122 \%$ more than national companies, and that firms with mixed capital innovate $161.4 \%$ more than national companies (which is the omitted variable). Exporting increases the probability to innovate for the world $148.5 \%$, relative to non-exporting companies; while the best predictor for this kind of innovations is, once again, the presence of an R\&D laboratory inside the firm. Finally, being an outsourcing company inhibits the innovation for the world $45.2 \%$.

The results of these regressions are consistent with the results presented in Tables 4 and 5 in the sense that companies that make innovation efforts inside the firms are the ones more prone to innovate, regardless of the relationship with the international economy. In this particular case, internationalization of the companies is a key factor for world innovation. This is not the same when product and process innovation in general are analyzed, because internationalization does not appear as a factor influencing innovation results.

\section{Discussion}

In order to facilitate the discussion of the previous results, Table 7 presents the outcomes of the fixed effects regressions and summarizes the findings in this research.

Table 7

Results of Regressions With Fixed Effects

\begin{tabular}{llll}
\hline Variable of internationalization & Innovation in product & Innovation in process & Innovation for the world \\
\hline $100 \%$ foreign capital & $\mathrm{n} / \mathrm{a}$ & $\mathrm{n} / \mathrm{a}$ & $121.98 \%$ \\
Mixed capital & $\mathrm{n} / \mathrm{a}$ & $\mathrm{n} / \mathrm{a}$ & $161.37 \%$ \\
Exporting & $\mathrm{n} / \mathrm{a}$ & $\mathrm{n} / \mathrm{a}$ & $148.55 \%$ \\
Importing & $\mathrm{n} / \mathrm{a}$ & $\mathrm{n} / \mathrm{a}$ & $\mathrm{n} / \mathrm{a}$ \\
Outsourcing & $-57.44 \%$ & $\mathrm{n} / \mathrm{a}$ & $-45.25 \%$ \\
\hline
\end{tabular}

Source: Own estimates based on the ESIDET 2010, INEGI.

It is worth to highlight the results in the first and the second column of Table 7, since the international diversification of a company in a developing country such as Mexico does not seem to promote the generation of new products and processes for the national market. Actually, this research found that an outsourcing company (of foreign ownership and which exports almost all of its production, after having added value through the labor factor) has a negative effect on the probability to innovate in product. Specifically, 
outsourcing companies innovate in product $57 \%$ less than the non-outsourcing companies. These first results contradict the findings in the works done in Germany and the United Kingdom, where the exporting companies promote the creation of new products, but confirm the results found by Damijan et al. (2010), in the sense that in the developing countries the exporting activity does not seem to promote the creation of new products. The case of process innovation is almost identical, since the exporting companies or the ones with foreign capital do not innovate more than the non-internationalized firms. This result contradicts the findings by Damijan et al. (2010) who found out that an exporting company facilitates the process innovation. However, it seems that exporting companies in a developing country such as Mexico are interested in generating innovations for the world since this opens new markets. The results of the regressions of fixed effects indicate that an exporting company has a probability to generate innovations for the world which is $148.5 \%$ higher than the probability to innovate for the world of a non-exporting company. Also the companies of mixed capital, i.e. those that combine foreign capital with the national, present $161.4 \%$ more probability to innovate for the world in comparison to the national companies. Besides, companies with $100 \%$ foreign capital innovate for the world $122 \%$ more than the national companies. Regarding the imports, the results of this paper are consistent with the idea by Grossman and Helpman (1991), that incorporating foreign inputs in the production do not have significant effects on the innovative capacity of the companies when the innovation refers to the generation of new products and processes for the domestic market. Finally, the results of Table 7 indicate that the outsourcing (maquila) companies are less prone to innovate in both products and for the world. It was found that the probability of product innovation of an outsourcing company is $57.4 \%$ less than the probability of product innovation of a non-outsourcing company, and that the probability to innovate for the world of an outsourcing company is $45.2 \%$ less than the probability to innovate for the world of a non-outsourcing company.

\section{Conclusions}

In 1985, Mexico started a process of integration with the international markets with the hope to generate higher rates of economic growth. Thirty years after starting this integration, the Mexican economy is characterized by a slow growth which calls into question the effect of the trade liberalization on the economic dynamics. A key factor for the economic growth is the technology innovation and the objective of this paper is to analyze the relationship of the internationalization of the productive plant with innovative efforts of the Mexican manufacturing sector. More specifically, it is attempted to understand the effect the internationalization has had on the creation of new products and new processes for the domestic market and on the generation of innovations for the world, since according to the growth theory, moving technological boundaries promotes greater productivity of the companies and this generates GDP growth.

In the literature, there are different researches which point out that in the developing countries the exposure of the national productive sector to international markets promotes technology adoption, but not the creation of new goods and new processes. Actually, in other researches, it has been shown that the FDI promotes lower technological innovation, and that the imports facilitate the imitation of the technology incorporated in the foreign products.

The Mexican manufacturing industry is characterized by its low innovation. According to the estimates in this paper, only $0.01 \%$ of the companies of this sector have incomes from sale of patented products, and only $2.65 \%$ declare to have done some innovation for the world. The descriptive analysis indicates that more than $30 \%$ of the Mexican manufacturing companies invest resources to generate new technology, but only $12.8 \%$ 
affirm to have reached any product innovation. When this is analyzed in more detail, it is found that the companies that have a contact with the international market, either by exporting part of their production or importing part of their inputs, by receiving foreign capital or by manufacturing products based on imported inputs, these "internationalized" companies tend to innovate much more than their national counterparts. This result required econometric exercises to better understand how the integration with the international market affects the innovative efforts of the analyzed productive units.

The results of three carried out econometric exercises are surprising. First, it draws attention that being an outsourcing company influences negatively the innovative activity of the firm, at least in terms of creation of new products or the generation of innovations for the world. This suggests that the model of economic integration based on this type of companies does not promote higher growth rates in the long run. According to the figures of the INEGI, an important part of the FDI is addressed to the establishing of outsourcing companies; therefore, the first public policy recommendation would be to review the destination of foreign resources. The economy of the border region of the country depends greatly on the maquiladora industry, therefore, it is likely that the regional rates of innovation are lower in this part of the national territory and so the growth rates.

Another interesting result of this research is that the exporting companies tend to make innovation for the world more than their non-exporting counterparts, but they do not innovate more in products and processes that are new either for the company or for the country. It is likely that the competition which the companies face on the international markets motivates them to generate innovations for the world to decrease costs or to open markets; however, they seem to prefer to export the already proven and successful products on these markets. Another public policy recommendation would be to promote foreign sales and to support the innovative efforts of the exporting companies. According to the presented results, only $18.6 \%$ of the companies from the national manufacturing sector send their production to the international markets. It is known that entering to a new market is not an easy task and the government can play an important role in this entering, therefore, it is recommended to promote the internationalization of the national companies by selling their products on foreign markets.

Regarding the FDI, the companies with $100 \%$ foreign capital in Mexico are not more prone to innovate in product and processes than their national counterparts, but they are definitely more innovative for the world. This suggests that in the multinational companies, the innovation is carried out both in their head offices and at subsidiary companies. This result contradicts other researches so it is surprising. An important finding is that the companies with mixed capital tend to innovate more for the world than the national companies. From this result, another policy recommendation can be derived, which is to boost the innovative effort of the national industry for the world by promoting foreign investment.

Finally, it was found that the importing companies are not more prone to innovate than their non-importing counterparts, so it can be concluded that this internationalization mode has no effect on the ability to generate developments in the country, and so on the growth rate of the economy in the long run.

Regarding R\&D laboratories, it has been found that this is the most important factor behind innovation in the Mexican manufacturing sector.

The results of this research do not support the idea that the foreign capital alone inhibits innovation as it is suggested in the researches realized in different developing countries. It draws attention that small companies appear to innovate more than larger production units, although other researches have already made this remark (see Meza \& Mora, 2005). 


\section{References}

Aghion, P., \& Howitt, P. (1998). Endogenous growth theory. Cambridge: MIT Press.

Almeida, R. K., \& Fernandes, A. M. (2008). Openness and technological innovations in developing countries: Evidence from firm-level surveys. Journal of Developing Studies, 44, 701-21.

Altomonte, C., Aquilante, T., Békes, G., \& Ottaviano, G. I. P. (2013). Internationalization and innovation of firms: Evidence and policy. Economic Policy, 26(76), 663-700.

Alvarez, R., \& Robertson, R. (2004). Exposure to foreign markets and plant-level innovation: Evidence from Chile and Mexico. The Journal of International Trade and Economic Development: An International and Comparative Review, 13(1), 57-87.

Anwar, S., \& Sun, S. (2103). Foreign entry and firm R\&D: Evidence from Chinese manufacturing industries. R\&D Management, 43(4), 303-317.

Becheikh, N., Landry, R., \& Amara, N. (2006) Lessons from innovation empirical studies in the manufacturing sector: A systematic review of the literature from 1993-2003. Technovation, 26, 644-664.

Bernard, A. (1999). Exceptional exporter performance: Cause, effect or both? Journal of International Economics, 47, 1-25.

Bertschek, I. (1995). Product and process innovation as a response of increasing imports and Foreign Direct Investment. The Journal of Industrial Economics, 43(4), 341-357.

Boermans, M. A., \& Roelfsema, H. (2015). The effects of internationalization on innovation: Firm level evidence for transition economies. Open Economy Review, 26, 333-350.

Cantwell, J. (1989). Technological innovation and multinational corporations. In B. Blackwell (Ed.).

Caselli, F., \& Coleman, W. II. (2001). Cross-country technology diffusion: The case of computers. American Economic Review, 91(2), 328-335.

Comin, D., \& Hobijn, B. (2004). Cross-country technology adoption: Making the theories face the facts. Journal of Monetary Economics, 51(1) 39-83.

Contractor, F. J., Kundu, S. K., \& Hsu, C. C. (2003). A three-stage theory of international expansion: The link between multinationality and performance in the service sector. Journal of International Business Studies, 34(1), 5-18.

Criscuolo, C., Haskel, J. E., \& Slaughter, M. J. (2010). Global engagement and the innovation activities of firms. International Journal of Industrial Organization, 28, 191-202.

Damijan, J. P., Kostevc, C., \& Polanec, S. (2010). From innovation to exporting or viceversa? World Economy, 33(3), 374-398.

Damijan, J. P., DeSousa, J., \& Lamotte, O. (2009). Does international openness affect the productivity of local firms? Economic Transition, 17(3), 559-586.

Dasgupta, P., \& Stiglitz, J. E. (1980). Industrial structure and the nature of innovative activity. Economic Journal, 90, $266-293$.

Griliches, Z. (1998). R\&D and productivity: Econometric results and measurement issues. In P. Stoneman (Ed.), Handbook of the economics if innovation and technological change (pp. 52-89). Oxford: Blackwell.

Grossman, G. L., \& Helpman, E. (1991). Innovation and growth in the world economy. Cambridge: MIT Press.

Haddad, M., \& Harrison, A. (1993). Are there positive spillovers from Foreign Direct Investment? Evidence from panel data for Morocco. Journal of Development Economics, 12, 51-74.

Haskel, J. E., Pereira, S., \& Slaughter, M. J. (2007). Does Inward Foreign Direct Investment boost the productivity of domestic firms? The Review of Economics and Statistics, 89(3), 482-496.

Hitt, M. A., Hoskisson, R. E., \& Kim, H. (1997). International diversification: Effects on innovation and firm performance in product-diversified firms. Academic Management Journal, 40(4), 767-798.

INEGI. (2013). Survey of research and technological development. ESIDET 2010 Results, pp. 1-2.

Insik, J. (2003). A cross-national study of the relationship between international diversification and new product performance. International Marketing Review, 20(4), 353-376.

Javorcik, B. (2006). Technological leadership and the choice of entry mode by foreign investors. In B. Hoekman and B. Javorcik (Eds.), global integration and technology transfer (pp. 179-206). Palgrave Macmillan and the World Bank.

Mansfield, E., \& Romeo, A. (1980). Technology transfers to overseas subsidiaries by US based firms. Quarterly Journal of Economics, 95(4), 737-750.

Meza, L., \& Mora, A. B. (2005). Trade and private R\&D in Mexico. Economía Mexicana Nueva Epoca, 14(2), 157-183.

OCDE. (1997). Proposed guidelines for collecting and interpreting technological innovation data. Oslo Manual (ed.). Paris: OCDE y Eurostat.

Qian, G., \& Li, J. (2002). Multinationality, global market diversification and profitability among the largest US firms. Journal of 
Business Research, 55(4), 325-335.

Ramachandran, V. (1993). Technology transfer, firm ownership, and investment in human capital. Review of Economics and Statistics, 75(4), 664-670.

Romer, P. M. (1990). Endogenous technological change. Journal of Political Economy, 98(5). Part 2: The Problem of Development: A Conference of the Institute for the Study of Free Enterprise Systems, pp. S71-S102.

Scherer, F. (1965). Firm size, market structure, opportunity and the output of patented inventions. American Economic Review, 55 (1965), 1097-1125.

Schumpeter, J. A. (1934). The theory of economic development. Cambridge, MA.: Harvard University Press.

Seker, M. (2012). Importing, exporting, and innovation in developing countries. Review of International Economics, 20(2), 299-314.

Thomas, D. E., \& Eden, L. (2004). What is the shape of the multinationality performance relationship? Multinational Business Review, 12(1), 89-110.

Zimmermann, K. (1987). Trade and dynamic efficiency. Kyklos, 40, 73-87. 